\title{
Partitioning evapotranspiration with concurrent eddy covariance measurements in a mixed forest
}

\section{Other Conference Item}

\section{Author(s):}

Paul-Limoges, Eugénie; Wolf, Sebastian (Di); Haghighi, Erfan; Schneider, Fabian; Longo, Marcos; Moorcroft, Paul; Gharun, Mana; Damm, Alexander

Publication date:

2019

Permanent link:

https://doi.org/10.3929/ethz-b-000370428

Rights / license:

Creative Commons Attribution 4.0 International

Originally published in:

Geophysical Research Abstracts 21 


\section{Partitioning evapotranspiration with concurrent eddy covariance measurements in a mixed forest}

Eugénie Paul-Limoges (1), Sebastian Wolf (2), Erfan Haghighi (1,3), Fabian Schneider (4), Marcos Longo (4), Paul Moorcroft (5), Mana Gharun (6), Alexander Damm (1,3)

(1) Department of Geography, University of Zurich, Zurich, Switzerland, (2) Institute of Terrestrial Ecosystems, ETH Zurich, Zurich, Switzerland, (3) Eawag, Swiss Federal Institute of Aquatic Science and Technology, Dübendorf, Switzerland, (4) Jet Propulsion Laboratory, California Institute of Technology, Pasadena, USA, (5) Department of Organismic and Evolutionary Biology, Harvard University, Cambridge, USA, (6) Institute of Agricultural Sciences, ETH Zurich, Zurich, Switzerland

Plants have an important effect on our climate: by assimilating $\mathrm{CO}_{2}$ through photosynthesis, plants mitigate increases in atmospheric $\mathrm{CO}_{2}$ concentrations, transfer water to the atmosphere and reduce surface temperatures. As atmospheric $\mathrm{CO}_{2}$ concentration increases, plants can reduce the opening of their stomata and still enhance photosynthesis. This $\mathrm{CO}_{2}$ fertilization effect can lead to increased growth but also to reduced transpiration rates, thereby contributing to warmer surface temperatures. There is ongoing debate on how these contrasting effects will influence our climate, in particular the contribution of forest ecosystems. It is however difficult to measure transpiration to understand these changes. Direct eddy covariance (EC) measurements are currently the best available approach to directly observe interactions linked to biosphere-atmosphere $\mathrm{CO}_{2}$ and water vapor exchange. While there are well-established methods to partition $\mathrm{CO}_{2}$ fluxes into the component fluxes of photosynthesis and respiration, there is still no standardized method to partition water vapor fluxes (evapotranspiration) into the component fluxes of evaporation and transpiration.

In this study, we are using two years of concurrent below and above canopy EC measurements in a mixed deciduous forest in Switzerland to partition water vapor fluxes into the biological transpiration and physical evaporation. We compare our results with evaporation modeled with the Haghighi \& Or (HO) model, and transpiration obtained from two models, namely the ecosystem demographic (ED2) and the Haghighi \& Kirchner (HK) transpiration models, as well as derived from plot-level sap flow measurements. We found that transpiration accounted on average for $80 \%$ of evapotranspiration, emphasizing a considerably lower contribution from evaporation. Mid-afternoon reductions in transpiration were found during periods of high vapor pressure deficit in summer. Despite pronounced differences in environmental conditions during the observed years, evapotranspiration and its transpiration component had a low inter-annual variability in this mixed forest. These results suggest a reliable access of the trees to water resources and stomatal regulation in response to enhanced atmospheric evaporative demand. Our results show the potential of concurrent below and above canopy EC measurements to partition evapotranspiration in forested areas. 